\title{
Borrelia and Chlamydia Can Form Mixed Biofilms in Infected Human Skin Tissues
}

\author{
E. Sapi ${ }^{1}$, K. Gupta ${ }^{1}$, K. Wawrzeniak ${ }^{1}$, G. Gaur ${ }^{1}$, J. Torres ${ }^{1}$, K. Filush ${ }^{1}$, A. Melillo ${ }^{1}$ and B. Zelger ${ }^{2}$ \\ ${ }^{1}$ Department of Biology and Environmental Science, University of New Haven, West Haven, CT 06516, USA \\ ${ }^{2}$ Department of Dermatology and Venereology, Medical University Innsbruck, Innsbruck, Austria
}

Received: 15 January 2019; accepted: 04 March 2019

\begin{abstract}
Our research group has recently shown that Borrelia burgdorferi, the Lyme disease bacterium, is capable of forming biofilms in Borrelia-infected human skin lesions called Borrelia lymphocytoma (BL). Biofilm structures often contain multiple organisms in a symbiotic relationship, with the goal of providing shelter from environmental stressors such as antimicrobial agents. Because multiple co-infections are common in Lyme disease, the main questions of this study were whether BL tissues contained other pathogenic species and/or whether there is any co-existence with Borrelia biofilms. Recent reports suggested Chlamydia-like organisms in ticks and Borrelia-infected human skin tissues; therefore, Chlamydia-specific polymerase chain reaction (PCR) analyses were performed in Borrelia-positive BL tissues. Analyses of the sequence of the positive PCR bands revealed that Chlamydia spp. DNAs are indeed present in these tissues, and their sequences have the best identity match to Chlamydophila pneumoniae and Chlamydia trachomatis. Fluorescent immunohistochemical and in situ hybridization methods demonstrated the presence of Chlamydia antigen and DNA in $84 \%$ of Borrelia biofilms. Confocal microscopy revealed that Chlamydia locates in the center of Borrelia biofilms, and together, they form a well-organized mixed pathogenic structure. In summary, our study is the first to show Borrelia-Chlamydia mixed biofilms in infected human skin tissues, which raises the questions of whether these human pathogens have developed a symbiotic relationship for their mutual survival.
\end{abstract}

Keywords: Lyme disease, biofilm, Borrelia lymphocytoma, alginate, chlamydia, confocal microscopy

\section{Introduction}

Lyme disease is a tick-borne illness that is caused by Borrelia burgdorferi sensu stricto and sensu lato in the United States and Europe, respectively [1-5]. Lyme disease is estimated to affect 300,000 people a year in the United States and 65,000 people a year in Europe [6]. The most common skin manifestation is a red rash that is observed after a tick bite called erythema migrans (EM) [7, 8]. The other well-studied dermatological conditions of Lyme disease are Borrelia lymphocytoma (BL) that appears in the early phase of Borrelia infection and acrodermatitis chronica atrophicans (ACA), which is the late onset cutaneous manifestation [9-12]. However, Lyme disease is a multi-systemic disease with manifestations that may also include other several chronic conditions such as Lyme carditis and neuroborreliosis [13-18].

Recently, our research group provided evidence for both the $B$. burgdorferi sensu stricto and the sensu lato groups of $B$. burgdorferi to exist in biofilm form in vitro and in vivo in Borrelia lymphocytoma [19-21]. Like other bacterial biofilms, Borrelia biofilms have shown increased resistance towards the standard antibiotics that are used to treat Lyme disease [22]. Biofilms are an aggregation of planktonic bacteria that attach on biotic and abiotic surfaces to form a three-dimensional architecture to withstand various environmental stressors [23]. The presence of a protective surface matrix called extracellular polymeric substance (EPS) and persister cells with low metabolic activity helps the survival of community inside the bio-

*Author for correspondence: 300 Boston Post Road, West Haven CT 06516; Tel.: +1-203-479-4552; E-mail: E-mail: esapi@newhaven.edu. film [24-30]. Clinically, biofilm infections represent a very significant problem due to the extraordinary resistance to both antimicrobial drugs, as well as host immune systems, which eventually could lead to persistent human infections [29, 31-33]. According to the National Institute of Health (NIH), $80 \%$ of all chronic infections have been linked to pathogenic biofilms [33, 34]. Several biofilm-related chronic infections have been reported such as Pseudomonas aeruginosa in cystic fibrosis [35], Escherichia coli in urinary tract infections, Staphylococcus aureus in osteomyelitis and endocarditis, and Streptococcus pneumoniae in pulmonary infections [33, 36-38].

Highly diverse in nature, biofilms have been reported to exist in a polymicrobial fashion, where several bacterial species along with fungi, yeast, and viruses reside in a community $[39,40]$. The microbial community communicates through quorum sensing, co-operates with each other by developing a symbiotic relationship, protects and fights against antimicrobial treatments $[39,40]$. The presence of mixed biofilms has been suggested in oral plaques, gastrointestinal tract, chronic wounds, and lungs, enhancing biofilm formation and increasing the resistance against stress and the host immune responses [41-44].

In Lyme disease, co-infections are common because ticks are well known to carry and transmit several human pathogenic microbes along Borrelia such as Bartonella, Ehrlichia, Babesia, Anaplasma, and even Mycoplasma species [45-49]. Recently, the presence of Chlamydia-like organisms was also reported by several studies in a significant fraction of Ixodes ricinus ticks [50-52]. Furthermore, the presence of Chlamydia DNAs in $68 \%$ of the skin biopsies obtained from patients with a suspected tick bite history was found [52]. The follow up

This is an open-access article distributed under the terms of the Creative Commons Attribution-NonCommercial 4.0 International License (https://creativecommons.org/licenses/by-nc/4.0/), which permits unrestricted use, distribution, and reproduction in any medium for non-commercial purposes, provided the original author and source are credited, a link to the CC License is provided, and changes - if any - are indicated. 
study from the same research group reported that all Borrelia positive granuloma annulare skin conditions were also positive for Chlamydia related bacteria [53]. Furthermore, a recent Australian study also confirmed that DNA from ticks contains DNA belonging to the chlamydial order genotype [54] suggesting that Chlamydia can be a very frequent co-infection in Borrelia infected tissues.

The bacterial order Chlamydiales includes intracellular Gram-negative bacteria that follow a biphasic development cycle and are dependent on the host organism for ATP synthesis [55]. The bacteria primarily exist as elementary bodies capable of invading the host cell [56]. Following infection in the host cell, they fuse with the membrane-bound cytoplasmic vacuole, termed inclusion bodies, where they are in a protective environment [56, 57].

There are 3 main Chlamydia pathogens responsible for causing human infections. Chlamydophila pneumoniae is a respiratory pathogen whose infection leads to extra-pulmonary symptoms such as myocarditis, atherosclerosis, reactive arthritis, and nervous system disorders [58, 59]. Chlamydia trachomatis is a bacterium responsible for causing sexually transmitted diseases such as urethritis, cervicitis, and some other infections, such as Reiter's syndrome, reactive arthritis, ocular infections, atypical pneumoniae, or pelvic inflammatory diseases [60]. Chlamydia psittaci is a pathogen that affects avians and is known to cause the human infection psittacosis leading to severe pneumonia [61]. Erythema nodosum, an inflamed skin condition with painful, red deep-seated nodules on lower legs, is also observed after chlamydial infection [62]. Several chlamydial infections have similar symptoms, as observed in Lyme patients such as arthritis, atherosclerosis, neurocognitive symptoms, and skin rashes [45, 63].

Chlamydia-related infections have been reported to be developing an emerging resistance to antibiotics in vitro and in clinical samples $[64,65]$. There is no direct evidence for the existence of Chlamydia in biofilm form; however, studies have reported the existence of chlamydial aggregates due to stressful conditions such as calcium imbalance [66, 67].

Based on these findings, the goal of this study was to investigate the potential presence of Chlamydia spp. in BL skin biopsies and their potential relationship to Borrelia biofilms reported previously in BL skin biopsies.

\section{Materials and Methods}

Human Skin Sections. From the files of our dermatohistopathologic laboratory, paraffin materials from 6 cases of clinically confirmed Borrelia lymphocytoma were archived from January 1975 to December 2005. All six cases had positive serology for Borrelia IgG and characteristic features of Borrelia lymphocytoma with "acral" predilection were found. All six patients were female (average age $=33$ years) from endemic areas of borreliosis in Austria with a rate of positive serology in the population between 30-60\%. Polymerase chain reaction (PCR) confirmation for all 6 cases was performed independently in 2 different laboratories located in Austria and the US. The archived hematoxylin-andeosin (H\&E)-stained sections were reexamined, and the previous diagnosis also confirmed. Institutional Review Board exemption for this study was obtained from the University of New Haven. The paraffin blocks were sectioned by McClain Laboratories LLC [Smithtown NY] at $4 \mu \mathrm{m}$ on TRUBOND200 adhesive slides. The sections then were deparaffinized by washing the sections three times in $100 \%$ xylene for $5 \mathrm{~min}$ each, followed by rehydration in a series of graded alcohols $(100 \%, 90 \%$, and $70 \%)$ and washed in $1 \times$ phosphate buffered saline (PBS) of $\mathrm{pH} 7.4$ for $5 \mathrm{~min}$. For the immunohistochemical experiments, the tissues were incubated in $10 \mathrm{mM}$ sodium citrate buffer for $45 \mathrm{~min}$ at $95{ }^{\circ} \mathrm{C}$ for antibody retrieval.

DNA Extraction. DNA extraction from FFPE samples was performed using the Qiagen Gene Read DNA FFPE Kit (Qiagen, Germantown, MD) according to the manufacturer's handbook with some modifications: $4-\mu \mathrm{m}$ paraffin-embedded tissue sections were deparaffinized by heating slides for $10 \mathrm{~min}$ at $45{ }^{\circ} \mathrm{C}$ followed by 3 xylene washes, 5 min each wash. Tissues were then rehydrated in a series of alcohol $(100 \%, 100 \%, 90 \%$, and $70 \%)$ washes for 3 min each. Slides were run under a slow stream of tap water in a container with $70 \%$ alcohol for $30 \mathrm{~min}$. Tissue sections were scraped into $1.5-\mathrm{mL}$ tubes using a sterile razor blade; the $56{ }^{\circ} \mathrm{C}$ proteinase $\mathrm{K}$ digestion step was performed for $72 \mathrm{~h}$; the AW1 and AW2 wash steps were performed three times.

Polymerase Chain Reaction. PCR reactions for Borrelia burgdorferi sensu lato were performed on all BL biopsy samples in previous studies by 2 independent laboratories [8, 21], and positive Borrelia afzelii DNAs were found on all 6 samples. To detect the specific Chlamydia spp. in the skin tissue samples, 2 different previously published PCR methods were used to maximize the probability to amplify Chlamydia spp. $[68,69]$. Both PCR protocols were designed to detect the Outer Membrane Protein A (OmpA) gene, which was proven to be specific enough to identify the different Chlamydia species [68, 69]. Positive control reactions consisted of commercially available DNA samples (not live cultures) from Chlamydophila pneumoniae strain CM-1 $\left[\mathrm{ATCC}^{\circledR} \mathrm{VR}-1360^{\mathrm{TM}}\right]$ and Chlamydia trachomatis, both obtained from American Type Culture Collection (ATCC) (Serovar E Chlamydiaceae VR 348BD BOUR strain). As negative controls, reactions with no template DNA and normal healthy human DNA samples were used. The first PCR protocol was slightly modified and included an additional pre-amplification of the OpmA DNA in the BL tissues in a nested PCR reaction. In the first round, primers specific to the outer membrane protein A (OmpA) gene were used: forward 5'-CGCATTTGCTGGTTCTGTT-3' and reverse 5'-CCAACGAGATTGAACGCTGT-3' primer sequences (Integrated DNA Technologies). In a $25 \mu \mathrm{L}$ reaction, $1 \times$ PCR buffer (Promega), $1.5 \mathrm{mM} \mathrm{MgCl}_{2}, 0.2 \mathrm{mM}$ dNTPs, $0.2 \mu \mathrm{M}$ forward primer, $0.2 \mu \mathrm{M}$ reverse primer, $1.25 \mathrm{U}$ of DNA polymerase, and $50 \mathrm{ng}$ of DNA template were added. Reaction conditions were defined by an initial denaturing time of $95{ }^{\circ} \mathrm{C}$ for $5 \mathrm{~min}$, followed by 35 cycles of $95{ }^{\circ} \mathrm{C} / 45 \mathrm{~s}$, $53{ }^{\circ} \mathrm{C} / 15 \mathrm{~s}, 55.4{ }^{\circ} \mathrm{C} / 15 \mathrm{~s}, 72{ }^{\circ} \mathrm{C} / 45 \mathrm{~s}$, and a final extension of at $72{ }^{\circ} \mathrm{C} / 5 \mathrm{~min}$. Primers for the nested reaction were as follows: forward 5'-CTCCTTACAAGCCTTGCCTGTAGGG-3', reverse 5'-GCGATCCCAAATGTTTAAGGC-3'. [68]. A $50 \mu \mathrm{L}$ nested PCR reaction was prepared by adding $1 \times$ Buffer B (Promega, Madison WI), $1.5 \mathrm{mM} \mathrm{MgCl} 2,0.2 \mathrm{mM}$ dNTPs, $0.2 \mu \mathrm{M}$ forward primer, $0.2 \mu \mathrm{M}$ reverse primer, $1.25 \mathrm{U}$ of DNA polymerase, and $1 \mu \mathrm{L}$ of a 1:100 dilution of the first reaction product. Reaction conditions were defined by an initial denaturing time of $95{ }^{\circ} \mathrm{C}$ for $5 \mathrm{~min}$, followed by 35 cycles of $95{ }^{\circ} \mathrm{C} / 60 \mathrm{~s}, 53.4{ }^{\circ} \mathrm{C} / 30 \mathrm{~s}, 72{ }^{\circ} \mathrm{C} / 60 \mathrm{~s}$, and a final extension of at $72{ }^{\circ} \mathrm{C} / 5 \mathrm{~min}$. The $337 \mathrm{bp}$ PCR products were analyzed by standard agarose gel electrophoresis, and the PCR products were purified using a QIAquick PCR purification kit (Qiagen, Germantown, MD) according to the manufacturer's instructions. Samples were eluted twice in $30 \mu \mathrm{L}$, and the eluates from each sample were pooled and sequenced in both directions twice ( $4 \times$ coverage) using the same primers that generated the products. All DNA sequencing was performed by Eurofins Genomics (Louisville, KY).

In the second PCR protocol, a different published primer pair spanning the major outer membrane protein (OmpA) 
region of the Chlamydia species was used (69). Primers were forward 5'-CCTGTGGGGAATCCTGCTGAA-3' and reverse 5'-GTCGAAAACAAAGTCACCATAGTA-3' flanking a $144 \mathrm{bp}$ region of the gene. For the PCR conditions, a final reaction volume of $50 \mu \mathrm{L}$ was set with $0.2 \mathrm{mM}$ dNTPs, $2.5 \mathrm{U}$ of Taq DNA polymerase (Invitrogen, Carlsbad CA), $0.2 \mu \mathrm{M}$ of each forward and reverse primer, $1.5 \mathrm{mM}$ of $\mathrm{MgCl}_{2}$, and $1 \times$ Buffer B (Promega, Madison WI). The temperature profile was set for initial denaturation at $94{ }^{\circ} \mathrm{C}$ for $4 \mathrm{~min}$, followed by 40 cycles of denaturation at $94{ }^{\circ} \mathrm{C}$ for $1 \mathrm{~min}$, annealing at $53{ }^{\circ} \mathrm{C}$ for $1 \mathrm{~min}$, and extension at $72{ }^{\circ} \mathrm{C}$ for $2 \mathrm{~min}$, followed by a final extension at $72{ }^{\circ} \mathrm{C}$ for $5 \mathrm{~min}$. The PCR products were analyzed by standard agarose gel electrophoresis, and the PCR products were purified using the QIAquick PCR purification kit (Qiagen, Germantown, MD) and sequenced as described above.

All resulting sequences were first analyzed using the Basic Local Alignment Search Tool on the NCBI website (BLAST, https://blast.ncbi.nlm.nih.gov/Blast.cgi). The sequences were aligned to reference sequences using the CLUSTEL OMEGA multiple sequence alignment tool (EMBL-EBI, http://www. ebi.ac.uk/Tools/msa/clustalo/).

Immunohistochemistry. Before proceeding with immunostaining, the deparaffinized slides were rinsed with $1 \times$ phosphate buffered saline (PBS, Sigma, St. Louise MO) and distilled water for $2 \mathrm{~min}$ each. Slides were pre-incubated with $10 \%$ normal goat serum (Thermo Scientific) in PBS- $0.5 \%$ bovine serum albumin (BSA, Sigma) for $30 \mathrm{~min}$ at room temperature (RT) to block the nonspecific binding of the secondary antibody. Slides were then rinsed twice with $1 \times$ PBS and distilled water for $2 \mathrm{~min}$ each at RT. The slides were then treated with a dilution of 1:200 (dilution buffer: PBS pH $7.4+0.5 \%$ BSA) of monoclonal antibody for Chlamydia spp. (Cat\# C65815M, Meridian Life Sciences, USA) and incubated overnight in a humidified chamber at $4{ }^{\circ} \mathrm{C}$. The slides then were washed in $1 \times$ PBS and distilled water five times for 2 min each at RT. The tissue sections were then incubated with a 1:200 dilution of the secondary anti-mouse antibody (dilution buffer: PBS pH $7.4+0.5 \%$ BSA) with a fluorescent red tag (goat anti-mouse IgG $(\mathrm{H}+\mathrm{L})$, DyLight 594 conjugated for an hour at RT in a humidified chamber. The excess solution around the tissue was gently wiped, washed five times as mentioned above with $1 \times$ PBS, and then, the polyclonal rabbit anti-alginate antibody (generously provided by Dr. Gerald Pier, Harvard Medical School) was diluted in a 1:500 ratio (dilution buffer: PBS pH $7.4+0.5 \%$ BSA) and added to the slides. The slides were incubated at RT overnight in a humidified chamber. The next day the slides were washed five times with $1 \times$ PBS for $2 \mathrm{~min}$ each. The tissue sections were then treated with a 1:200 dilution (dilution buffer: PBS $\mathrm{pH} 7.4+0.5 \%$ BSA) of the secondary anti-rabbit antibody with a fluorescent blue tag (goat anti-rabbit $\operatorname{IgG}(\mathrm{H}+\mathrm{L})$, DyLight 405 conjugated) and incubated for an hour. This step was followed by the abovementioned washes and then treatment with a 1:50 dilution of a fluorescein isothiocyanate (FITC)-labeled polyclonal rabbit anti-Borrelia burgdorferi antibody (PA-1-73005, Thermo scientific), for an hour in a humidified chamber at room temperature. The slide sections were then washed and processed as mentioned above and then counterstained with $0.1 \%$ Sudan black (Sigma) for $20 \mathrm{~min}$, washed again, and then mounted with PermaFluor (Thermo Scientific). Images were taken and processed using a Leica DM2500 fluorescence microscope at $200 \times$ and $400 \times$ magnification.

As negative controls, commercially available human newborn foreskin tissue sections and healthy human skin sections (Biomax, HuFPT136) were stained following the same procedure as mentioned above. Additional negative controls such as omitting the primary antibody and the use of non-specific isotype $\operatorname{IgG}$ controls (IgG1 Isotype Control, Invitrogen, MA1-10406) were also utilized to confirm the specificity of the antibodies.

Fluorescent in situ Hybridization (FISH). The paraffinembedded tissue sections were deparaffinized and hydrated in a series of alcohol washes as mentioned above. The tissue sections were then placed in a solution of sodium borohydride for $20 \mathrm{~min}$ on ice. Tissues were fixed with $4 \%$ paraformaldehyde (PFA, J.T Baker) for $15 \mathrm{~min}$ at RT. Next, the sections were washed with $2 \times$ saline sodium citrate (SSC) buffer for $5 \mathrm{~min}$ and digested with $100 \mathrm{ug} / \mathrm{mL}$ of proteinase $\mathrm{K}$ (Sigma) at RT for $15 \mathrm{~min}$. The slides were then treated with denaturing solution $(70 \% v / v$ formamide and $2 \times \mathrm{SSC})$ and incubated for $5 \mathrm{~min}$ at $95{ }^{\circ} \mathrm{C}$ and at RT. The slides were fixed again with 4\% PFA for $10 \mathrm{~min}$ at RT and washed with $2 \times$ SSC before being again placed in denaturing solution at $60{ }^{\circ} \mathrm{C}$ for $2 \mathrm{~min}$. The salmon sperm DNA (2.5 ng, Thermo Fisher Scientific) was prewarmed at $95{ }^{\circ} \mathrm{C}$ for $5 \mathrm{~min}$ and added to the slides for blocking for an hour at $48{ }^{\circ} \mathrm{C}$. The slides were then incubated with previously validated fluorescent in situ DNA probes [21, 70]: Borrelia-specific 16S rDNA probe (FAM-5'-GGATATAGTTAGAGATAATTATTCCCCGTTTG$3^{\prime}$ ) and Chlamydia-specific 16S rDNA probe (Alexa 568 5'CCTCCGTATTACCGCAGC-3') after denaturing the probes at $95{ }^{\circ} \mathrm{C}$ for $10 \mathrm{~min}$. A coverslip was placed on the slide to ensure that the tissue did not dry out, and the tissue sections were incubated for $16 \mathrm{~h}$ overnight at $48{ }^{\circ} \mathrm{C}$. After overnight incubation, the coverslip was removed by placing the slides in $2 \times \mathrm{SSC}$ for $5 \mathrm{~min}$, followed by five-time washes of $0.2 \times \mathrm{SSC}$ buffer for $5 \mathrm{~min}$ each at RT in the dark. Sections were then counterstained with $0.1 \%$ Sudan black dye (Sigma) for $20 \mathrm{~min}$ in the dark at RT. The slides were washed five times with $2 \times$ SSC for $5 \mathrm{~min}$ before mounting the slides with PermaFluor mounting media (Thermo Scientific) and stored at $4{ }^{\circ} \mathrm{C}$. Images were taken using a Leica DM2500 fluorescence microscope at $200 \times$ and $400 \times$ magnification.

All FISH steps were repeated with several negative controls such as the following: 1) $100 \mathrm{ng}$ random oligonucleotide, (5'FAM-GCATAGCTCTATGACTCTATACTGGTACGTAG-3'), 2) $200 \mathrm{ng}$ of unlabeled competing oligonucleotide added before the hybridization step [competing Borrelia (5'-CAAACGGGGAATAATTATCTCTAACTATATCC-3') and competing Chlamydia (5'-CCTCCGTATTACCGCGGC-3')], and 3) a DNase treatment of the sections before the hybridization step to digest all genomic DNA $(100 \mu \mathrm{g} / \mathrm{mL}$ for $60 \mathrm{~min}$ at $37^{\circ} \mathrm{C}$ ).

A combination of immuno and in situ protocols was performed in a similar fashion as described earlier [21]. Briefly, after the $0.2 \times \mathrm{SSC}$ wash in the FISH protocol the sections were blocked with a 1:200 dilution of goat serum (Thermo Scientific) for an hour at RT in a humidified chamber. The slides were washed five times with PBS followed by adding the primary polyclonal anti-alginate antibody for overnight incubation at RT. The next day the slides were tagged with a 1:200 dilution of the secondary anti-rabbit antibody with a fluorescent blue tag (goat anti-rabbit IgG $(\mathrm{H}+\mathrm{L})$, DyLight 405 conjugated) and incubated for an hour at RT. This step was then followed by a counterstaining step with $0.1 \%$ Sudan black for $20 \mathrm{~min}$, followed by several washes in $0.2 \times \mathrm{SSC}$ and mounting with PermaFluor mounting media (Thermo Scientific) and storing at $4{ }^{\circ} \mathrm{C}$. Images were taken using Leica DM2500 fluorescent microscope at $200 \times$ and $400 \times$ magnification.

Confocal Microscopy. The tissue sections were visualized and scanned with a confocal scanning laser microscope (Leica 
DMI6000) for generating $z$-axis stacks for visualization of the dual species biofilm in a three-dimensional view. ImageJ software was used to process the generated $z$ stacks in order to receive a detailed analysis of the spatial distribution of the multi-species biofilms (Plugins: Interactive 3D Surface Plot and Volume Viewer).

Ethics. The study used archived paraffin embedded sections which was sent to University of New Haven without any identification. The Institutional Review Board at the University of New Haven approved the study under 45 CFR 46.101(b)(4): Research involving the collection or study of existing data, documents, records, pathological specimens, or diagnostic specimens, if these sources are publicly available or if the information is recorded by the investigator in such a manner that subjects cannot be identified, directly or through identifiers linked to the subjects.

\section{Results}

PCR Analyses of Borrelia-Positive BL Skin Tissues for Chlamydia spp.. The first aim of the study was to evaluate the potential presence of Chlamydia spp. in the Borreliapositive biopsy tissues of BL patients. We used archived skin biopsies from our previous studies, in which we proved that the BL tissues are positive for Borrelia afzelii DNA using PCR methods performed by two independent research laboratories previously [8, 21]. To amplify Chlamydia spp. DNA, several previously published PCR protocols were utilized which were designed to amplify the major outer membrane protein A (OmpA) gene and were able to identify the species [68, 69]. The Chlamydia OmpA-specific PCR protocols resulted in positive bands in the BL tissues studied. Interestingly, when the DNAs were sequenced and analyzed by Basic Local Alignment Search Tool (BLAST, bioinformatics tool on NCBI website), the results revealed that multiple Chlamydia species were present in the Borrelia-infected BL skin tissues. In some of the BL tissues (4 out 6 samples), we were able to identify a common sequence with $99 \%$ identity to C. pneumoniae (KC512913; 98\% coverage with E value: 7e-151), 86\% identity to C. psittaci (KM247620; in 64\% coverage with E value: $1 \mathrm{e}-61$ ), and $76 \%$ to $C$. trachomatis (EU040365, in $71 \%$ of coverage and $\mathrm{E}$ value: 1e-40). The sequences were further analyzed by Clustal Omega multiple sequence alignment tool on the EMBL-EBI server (https://www.ebi.ac.uk/Tools/msa/ clustalo/). Figure 1A shows a representative multiple sequence alignment of the BL Chlamydia OmpA sequence to the pathogenic Chlamydia sequences.

Using another published OmpA PCR protocol [69], we amplified a significantly different common sequence in some of the BL tissue samples (2 out 6 samples), showing 97\% identity to $C$. trachomatis (JX559522; 93\% coverage with E value $9 \mathrm{e}-50$ ), $81 \%$ to $C$. psittaci (HM214490, in $67 \%$ of coverage

A

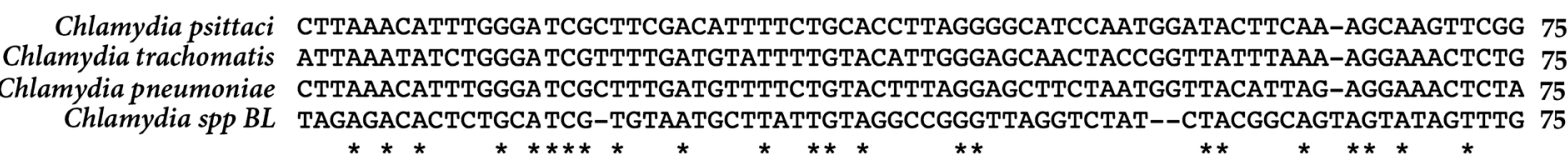

Chlamydia psittaci CTGCATTCAACTTGGTTGGGTTAATAGGGTTTTCAGCTGCAAGCTCAATCTCTACCGATCTTCCAACGCAACTTC 150 Chlamydia trachomatis СTTCCTTCAACTTAGTTGGATTATTCGGAACAAAAACACAATCTTCTAGCTTTA---ATACAGCGAAGCTTATTC 150 Chlamydia pneumoniae CAGCGTTCAATCTCGTTGGTTTATTCGGAGTTAAAG------GTACTA-CTGTA-----AATGCAAATGAACTAC 150 Chlamydia spp BL CAGCAGCGGATCCAGTAGGCTTGGCTCCCATAGAAA----ATGTTTTAGGTGCATCTACT TTTAAGATACGGTCG 150 $* * * * * * * * \quad * *$

Chlamydia psittaci CTAACGTAGGCATTACCCAAGGTGTTGTGGAATTTTATACAGACACATC---ATTTTCTTGGAGCGTAGGTG-CA 225 Chlamydia trachomatis CTAACACTGCTTTGAATGAAGCTGTGGTTGAGCTTTATATAAACACTAC---CTTTGCTTGGAGCGTAGGTG-CT 225 Chlamydia pneumoniae CAAACGTTTCTTTAAGTAACGGAGTTGTTGAACTTTACACAGACACCTC---TTTCTCTTGGAGCGTAGGCG-CT 225 Chlamydia spp BL AAAACATAGTCTCCGTAAAATCCAGCACGTAAGCTAATAGCGTCGCACCAAGTAGCGCAAGGATCGCAAGGATCT 225 $* * * * * * * * * * * * * * * * *$

Chlamydia psittaci CGTGGAGCTTTATGGGATGTGGTTGTGCAACTTTAGGAGCTGAGTTCCAATACGCTCAATCTAATCCTAAGATT 300 Chlamydia trachomatis CGTGCAGCTCTCTGGGAATGTGGGTGTGCAACGTTAGGAGCTTCTTTCCAATATGCTCAATCTAAACCTAAAGTA 300 Chlamydia pneumoniae CGTGGAGCCTTATGGGAATGCGGTTGTGCAACTTTGGGAGCTGAATTCCAATATGCACAGTCCAAACCTAAAGTT 300 Chlamydia spp BL CCTGCAGCACCTTCCCA-TATTGTACCATC AATTAATAAGCTTGGATCAGAAGGGTTCCCTACAGGCAAGGTTT 300

Chlamydia psittaci GAAATGCT 308 Chlamydiatrachomatis GAAGAGTT 308
Chlamydia pneumoniae GAAGAACT 308
Chlamydia spp BL GTAAGGAG 308 * *

B

Chlamydia spp BL GATCGACTGATTCTGTGGGAGGTTTCGGCGGAGATCCTTGCGATCCTTGCACCACTTGGT 60 Chlamydia trachomatis TCGACGGAATTCTGTGGGAAGGTTTCGGCGGAGATCCTTGCGATCCTTGCACCACTTGGT 60 Chlamydia psittaci TCGATGGCACTATGTGGGAAGGTGCTTCAGGAGATCCTTGCGATCCTTGCGCTACTTGGT 60 Chlamydia pneumoniae TTGATGGTACAATATGGGAAGGTGCTGCAGGAGATCCTTGCGATCCTTGCGCTACTTGGT 60 $* * * * * * \quad * * * * * * * * * * * * * * * * * * * * * * * * * * * * *$

Chlamydia spp BL GTGACGCTATCAGCATGCGTATGGGTTACTATGGTGACTTTGTTTTCGACAACACAAC 118 Chlamydia trachomatis GTGACGCTATCAGCATGCGTATGGGTTACTATGGTGACTTTGTTTTCGACCGTGTTTT 118 Chlamydia psittaci GTGACACCATTAGCATCCGCGCAGGATACTACGGAGATTATGTTTTCGATCGTGTATT 118 Chlamydia pneumoniae GCGACGCTATTAGCTTACGTGCTGGATTTTACGGAGACTATGTTTTCGACCGTATCTT 118

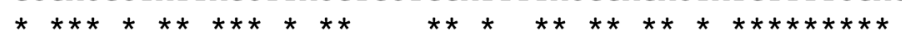

Figure 1. (A) A multiple sequence alignment obtained from Clustal Omega analyses representing BL Chlamydia OmpA DNA sequence mapped against different Chlamydia strains of Chlamydia psittaci (KM247620), Chlamydia trachomatis (EU040365), and Chlamydia pneumoniae (KC512913). (B) Clustel Omega multiple sequence alignment of OmpA gene DNA sequences obtained from BL tissues against different Chlamydia strains such as Chlamydia trachomatis (JX559522), Chlamydia psittaci (HM214490), and Chlamydia pneumoniae (DQ358972). Asterisks represent identical nucleotide sequence in all four Chlamydia sequences 
and $\mathrm{E}$ value $2 \mathrm{e}-19$ ), and $79 \%$ identity to $C$. pneumoniae (DQ358972; in $80 \%$ coverage with E value $2 \mathrm{e}-20$ ).

Figure 1B shows a multiple sequence alignment obtained from Clustal Omega EMBI/EBI server representing DNA sequences from BL tissue OmpA DNA samples mapped against 3 strains of Chlamydia trachomatis (JX559522), Chlamydia psittaci (HM214490), and Chlamydia pneumoniae (DQ358972).

Immunohistochemical (IHC) Staining of Human Biopsy Skin Tissues for Borrelia and Chlamydia. To further prove the presence of Chlamydia species and to determine whether there is a potential co-existence of the previously identified Borrelia biofilms found in these BL biopsy tissues [21], IHC staining techniques were used which were specific for Borrelia, Chlamydia, and alginate (biofilm marker) antigens.

Figure 2 shows that positive immunostaining for Borrelia (Figure 2, panels A, F, and K, green arrows,) and for the biofilm-specific marker alginate (Figure 2, panels $\mathrm{C}, \mathrm{H}$, and $\mathrm{M}$, blue arrows) is present in all $6 \mathrm{BL}$ biopsy tissues. For some tissue sections, the Borrelia-alginate positive aggregates also showed positive co-staining for Chlamydia spp. (Figure 2, Panels B and G, red arrows); however, some of the tissue sections only stained positive for Borrelia and alginate (Figure 2, panels K and M) but not for Chlamydia (Figure 2, panel L). Crucially, there was no immunostaining for Chlamydia spp. in the biofilm-free regions of tissues; however, Borrelia spirochetes were found frequently in the vicinity of the biofilm structures (Figure 2, panels $\mathrm{A}, \mathrm{F}$, and $\mathrm{K}$ green arrowheads). As reported previously [21, 22], those spirochetes were all negative for alginate antibody [Figure 2, panels $\mathrm{C}, \mathrm{H}$, and $\mathrm{M}$ ].

All of the IHC experiments included 2 independent negative controls to prove the specificity of antibodies: non-specific IgG antibody and normal human skin samples. No signal was observed in the BL skin tissues when non-specific antibody was used in the IHC procedure (Figure 2, panels D, I, $\mathrm{N}, \mathrm{S}$, and Y). Furthermore, there were no immunostaining on the 20 commercially purchased human foreskin (Figure 2, panels $\mathrm{P}, \mathrm{Q}, \mathrm{R}, \mathrm{S}$, and $\mathrm{T}$ ) and 20 healthy skin tissue sections (Figure 2, panels V, W, X, Y. and Z) for Borrelia and Chlamydia, as well as alginate antigens. To demonstrate the structure of the biofilm and how it is embedded in the tissue, the morphology of the BL skin tissues was visualized using a differential interference contrast microscopy method (DIC; Figure 2, panels E, J, O, T, and Z).

All images are taken with relatively low magnification $(200 \times)$ to demonstrate the biofilm surrounding tissues and to show the background signals of the IHC methods.

To further analyze and understand the frequency of co-existence of Chlamydia spp. in Borrelia biofilms, an additional 150 sections were stained using IHC staining procedures described above. Figure 3 shows representative images of Borrelia/alginate and Chlamydia-positive staining biofilms; a higher magnification $(400 \times)$ is used than that used in Figure 2 for a better visualization of their structures. Borrelia-positive aggregates were seen in all BL skin tissue samples (Figure 3, panels A, E, I, M, and R, green arrows, ref). Those structures were also stained positive for alginate, showing that they are indeed biofilms (Figure 3, panels C, G, K, O, and T, blue arrows). Most Borrelia and alginate positive structures stained positive for Chlamydia (Figure 3, panels B and F, red arrows). However, not all of those biofilm structures were positive for Chlamydia which further shows the specificity of our IHC protocol, (Figure 3, panels J, N, and S). The differential interference images depict the tissue morphology and the structure of the biofilm (Figure 3, panels D, H, L, P, and V).
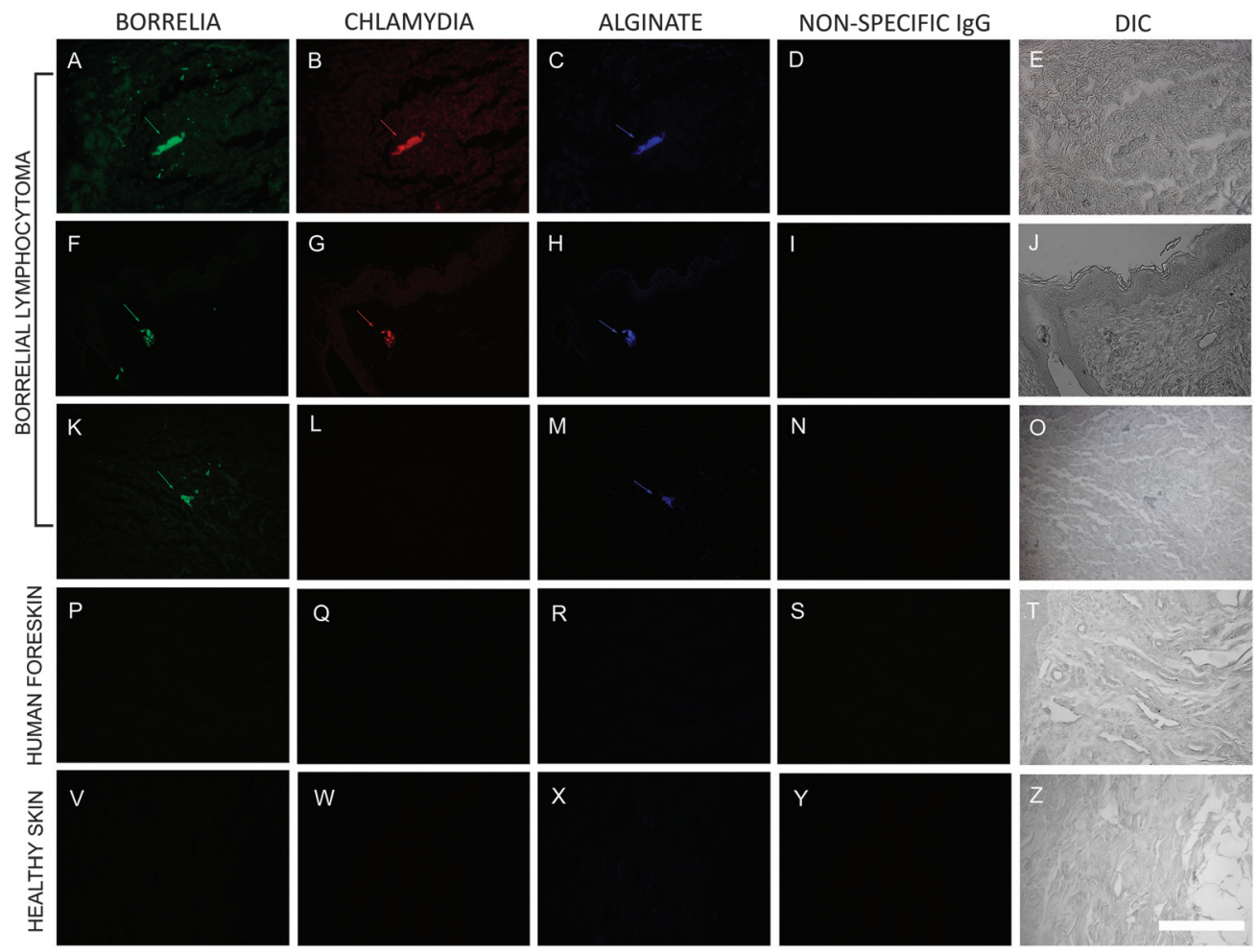

Figure 2. Representative IHC images of Borrelia, Chlamydia, and alginate staining in Borrelia-infected BL skin tissues. Panels A, F, K, P, and V show IHC staining results of skin tissues using a FITC labeled anti-Borrelia antibody (green arrows and arrowheads). Panels B, G, L, Q, and W show staining results with anti-chlamydia antibody (red arrows). Panels C, H, M, R, and X show staining of anti-alginate antibody (blue arrows). Panels D, I, N, S, and Y show results of staining with non-specific IgG antibody. Panels E, J, O, T, and Z are the differential interference contrast (DIC) images that show the morphology of the tissues. Panels A-O corresponds to BL skin tissues while panels P-T include negative controls corresponding to skin tissues from healthy human foreskin, and panels V-Z include negative controls corresponding to healthy skin tissues. All images were taken at $200 \times$ magnification. Scale bar: $200 \mu \mathrm{m}$ 

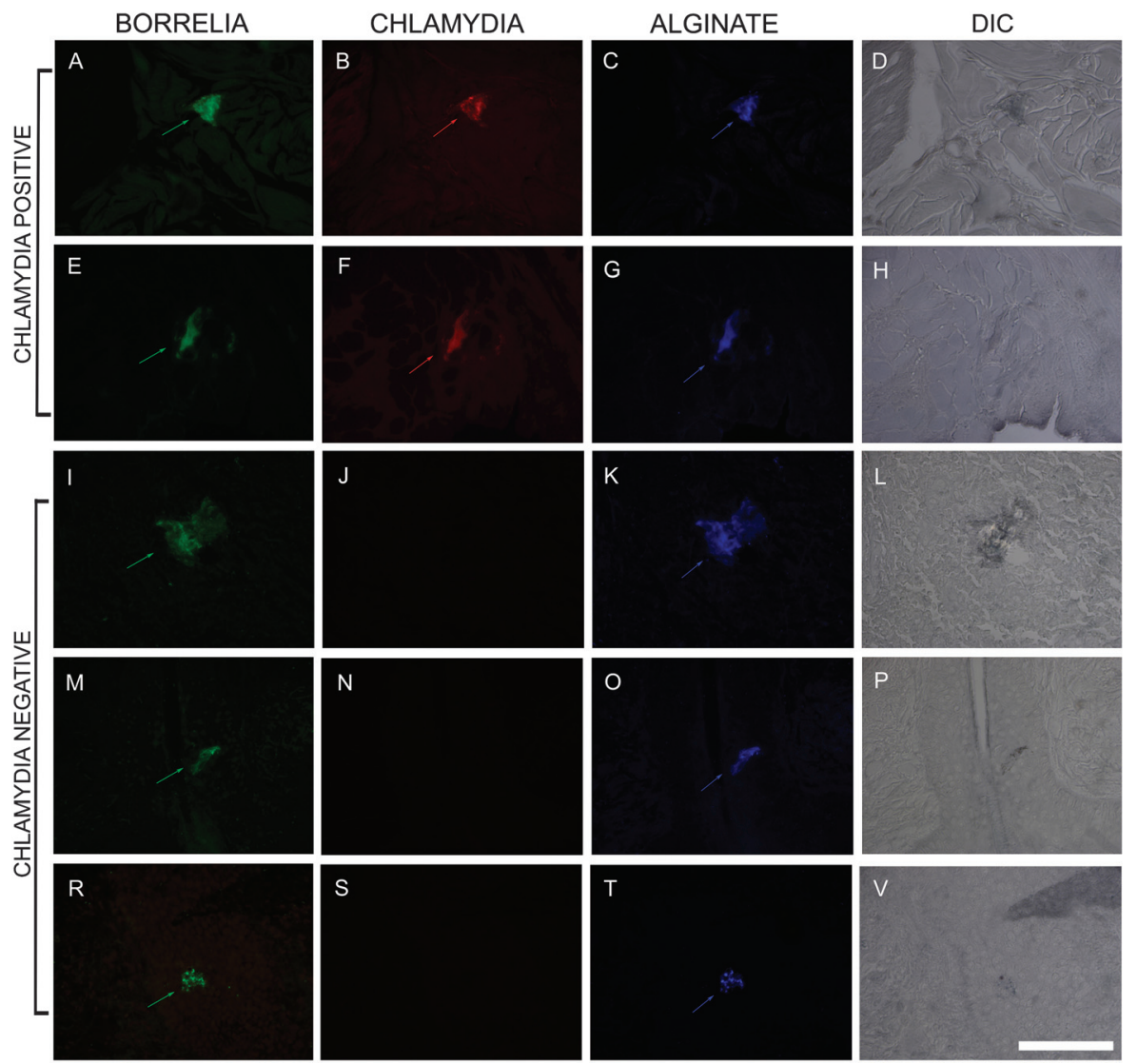

Figure 3. Representative images of IHC staining of BL biopsy skin tissues with Borrelia, Chlamydia, and alginate-specific antibodies. Panels A, E, I, M, and R show IHC positive staining for Borrelia (green arrows), and panels B and F show positive staining of Chlamydia (red arrows), while panels J, N, and S show negative staining for Chlamydia spp. Panel C, G, K, O, and T depict positive staining for alginate (blue arrows). Panel D, H, L, P, and V show DIC images. All images were taken at 400× magnification. Scale Bar: $200 \mu \mathrm{m}$

Quantitative analysis of a total of 150 IHC stained slides was carried out to categorize the size and frequency of the colocalization of Borrelia biofilms with Chlamydia spp. in BL skin tissues by direct counting of the positive structures. Each slide contained 2-4 biofilms and each biofilm size varied from a range of $20-80 \mu \mathrm{m}$.

Approximately $84 \%$ of Borrelia positive biofilms were positive for co-existence with Chlamydia spp. (Figure 4).

FISH Staining of Human Biopsy Skin Tissues for Borrelia and Chlamydia. To further confirm the results obtained

\section{Quantitative Analysis of Borrelia biofilms}

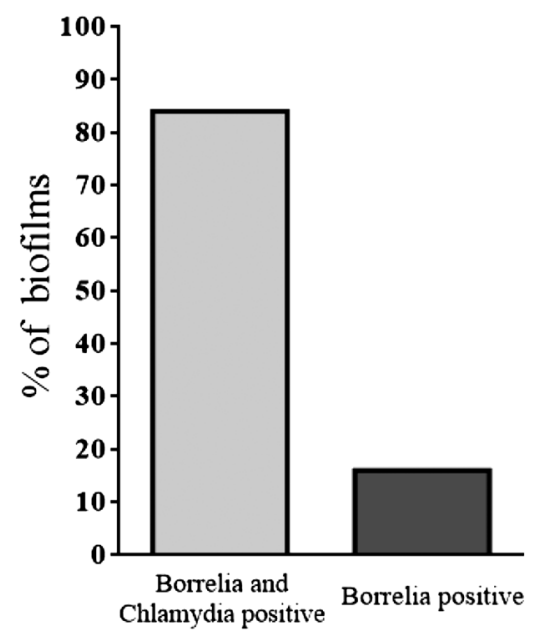

Figure 4. Quantitative analysis of Borrelia biofilms for positive Borrelia and Chlamydia IHC staining by IHC staining, fluorescent in situ hybridization (FISH) methods were utilized. FISH probes specific for $16 \mathrm{~S}$ rDNA of Borrelia and Chlamydia were chosen from previously validated studies [21, 70]. For each slide containing structures, IHC-positive for Borrelia (green staining, Figure 5, panel A) that co-stained with Chlamydia spp. antibody (red staining, Figure 5, panel B) and with the biofilm marker alginate (blue staining, Figure 5, panel C), the next consecutive slide was stained using a combined IHC and FISH technique. The Borrelia-species-specific 16S rDNA probe (green staining, Figure 5, Panel E) was co-localized with the ChlamydiaDNA-specific 16S rDNA probe (red staining, Figure 5, panel F). The Borrelia/Chlamydia-positive structures also stained positive for IHC staining using anti-alginate antibody which confirmed the co-localization of Borrelia biofilms with Chlamydia spp. in the BL skin tissues. Several negative controls were included in the study to confirm the specificity of the chosen FISH probes with our target organisms. Competing oligonucleotide probes showed no significant staining for both Borrelia (Figure 5, panel I) and Chlamydia (Figure 5, panel J). As additional negative controls, a random DNA probe (Figure 5, panel K) and a DNAse I pre-treated sample (Figure 5, panel L) were used which resulted in no significant staining. The tissue morphology was visualized using the DIC images, which show how the biofilm is embedded in the tissue (Figure 5, panels D and $\mathrm{H}$ ).

Confocal Imaging of Borrelia and Chlamydia Positive Tissues. A tissue section that was IHC positive for co-existence of Borrelia and Chlamydia and for the biofilm marker alginate (Figure 6, panels A, B, and C) were scanned with a confocal scanning laser microscope (Leica DMI6000) to further analyze the structure of the biofilm in the BL skin tissues 

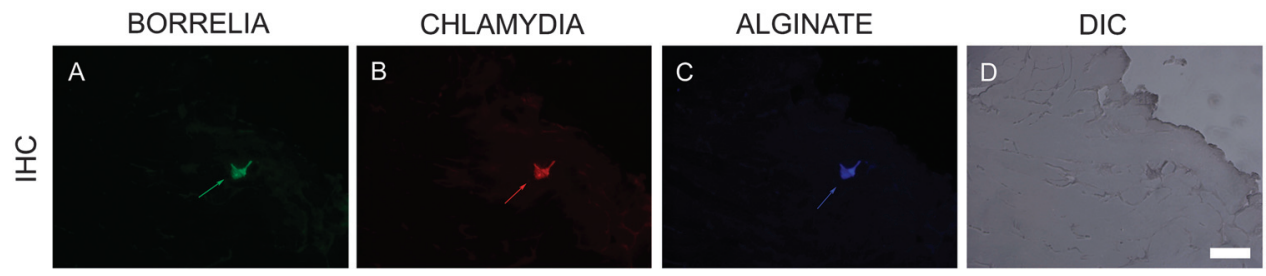

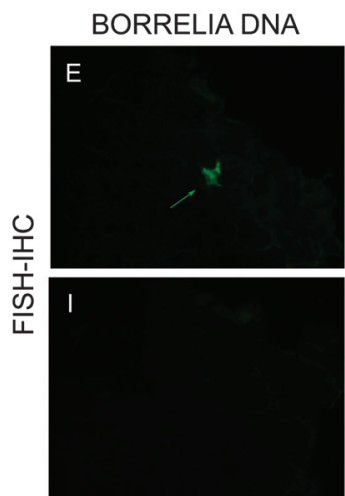

BORRELIA DNA+ COMPETING OLIGO
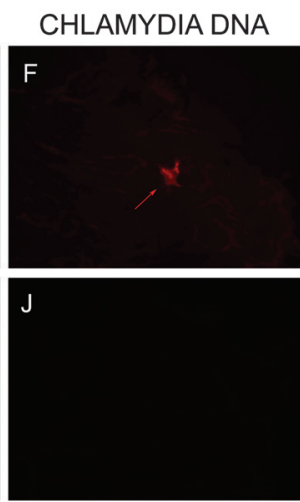

CHLAMYDIA DNA+ COMPETING OLIGO

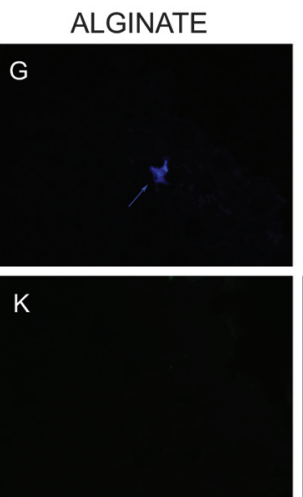

RANDOM PROBE

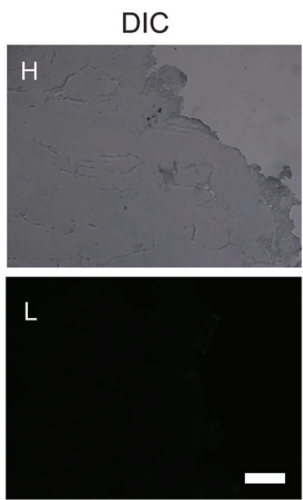

BORRELIA DNA+ CHLAMYDIA DNA+ DNASE I

Figure 5. Representative images of the IHC staining on BL skin tissue section and the images of the consecutive slides stained with combined fluorescent in situ hybridization (FISH) and IHC techniques. Panels A, B, and C are the results of skin tissues stained with antibodies against Borrelia (green arrow), Chlamydia (red arrow), and alginate (blue arrow), respectively. Panels E and I show the staining results of skin tissues with 16S rDNA probe for Borrelia burgdorferi (green arrow). Panels F and J show the staining results of skin tissues with 16S rDNA probe for Chlamydia spp. (red arrow). Panel G is stained with antibodies for alginate (blue arrow). Panels D and H depict the morphology of the skin tissues using DIC microscopy methods. As comprehensive negative controls, a competing oligonucleotide (panels I and J for Borrelia and Chlamydia, respectively), a random DNA probe (panel K), and a DNase-treated samples (panel L) were used on consecutive tissue sections to further show the specific city of the 16S rDNA probe (for further details of the experimental conditions can be in Materials and Methods). All images were taken at $400 \times$ magnification. Scale bar: $100 \mu \mathrm{m}$

in a three-dimensional view. The obtained image shows the spatial distribution and the integrity of the biofilm along with the individual $\mathrm{Z}$ stacks further providing evidence for Borrelia and Chlamydia co-existence in the Borrelia/alginate positive structure (Figure 6, panel E, F, and G). The individual Z stacks show aggregates of Chlamydia enclosed within the center of Borrelia biofilm (Figure 6, panel F, red arrows). The individual $\mathrm{Z}$ stacks of Borrelia and alginate show how alginate, a component of the EPS layer, surrounds the Borrelia biofilm (Figure 6, panel G, blue arrow).

\section{Discussion}

Previous studies have shown that Borrelia burgdorferi sensu stricto and the sensu lato group are capable of forming biofilms in vitro $[19,20]$. Recently, we also provided in vivo evidence for the presence of Borrelia burgdorferi biofilms in

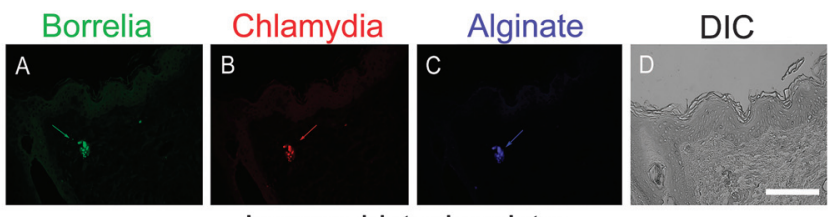

Immunohistochemistry
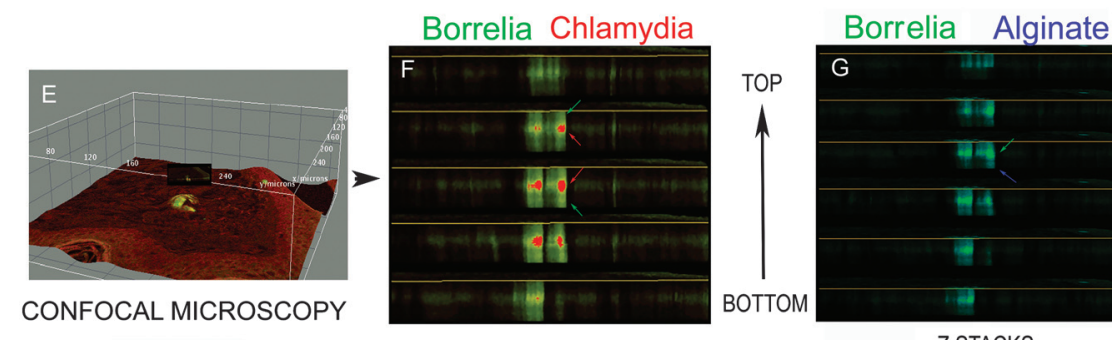

Z STACKS

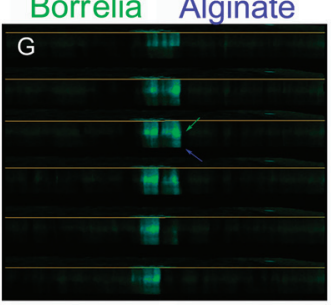

ZSTACKS

Figure 6. Three-dimensional (3D) analyses of Borrelia and Chlamydia mixed biofilm in human BL skin biopsy tissue using confocal microscopy. Panels A, B, and C are the results of skin tissues positively immunostained with antibodies against Borrelia (green arrow), Chlamydia (red arrow), and alginate (blue arrow), respectively. Panel D shows the DIC image to depict the morphology of the tissue. Confocal microscopy shows the 3D distribution of mixed biofilms and the individual Z stacks focus on the biofilms showing Borrelia and Chlamydia (panel F) and Borrelia and alginate (panel G) spatial distribution. Scale bar: $100 \mu \mathrm{m}$ 
Borrelia-infected skin lesions called Borrelia lymphocytoma (BL) [21]. However, the question of co-existence of Borrelia biofilms in the multi-species form is yet to be answered. This study investigated the presence of potential co-infections of Borrelia biofilms with Chlamydia spp. It is among the first to document the co-existence of Borrelia biofilms with the intracellular pathogen Chlamydia spp. in infected human skin tissues, and to the best of our knowledge, this is the first study to show Chlamydia within the biofilm.

Our PCR and sequencing analyses showed that Borrelia positive BL tissue samples are also positive for Chlamydia DNA, and the obtained sequencing was mapped to several chlamydial strains and was found to have the best match to 2 human pathogens, C. pneumoniae and C. trachomatis strains. Studies conducted in Finland and Australia reported Chlamydia-like DNA in skin biopsies of patients suspected to have a tick bite and who were PCR-positive for Borrelia DNA as well [50-52]. A very recent study provided evidence that IgM and IgG antibodies for both C. pneumoniae and C. trachomatis can be detected in $20-30 \%$ of patients with tick bite history [71]. Those studies strongly indicated that co-infection of Borrelia with Chlamydia spp. is possible.

After finding chlamydial DNA in BL skin biopsies, the question became whether they exist in biofilm form. To examine BL skin lesions for co-existence of Borrelia and Chlamydia in biofilm form, IHC staining and FISH techniques were used.

As previously reported, alginate is successfully being adapted as a biofilm marker and was used to confirm the coexistence of both bacterial species in the biofilm form [19]. Alginate has been reported to be a key component of the EPS layer in Borrelia burgdorferi sensu stricto and sensu lato biofilms [19-21]. Although no direct evidence suggests the existence of Chlamydia individually in a biofilm form, they could be a part of a microbial community with other bacterial biofilms. Biofilm forming bacteria can promote the participation of strains of non-biofilm forming bacteria in a community as is observed in dental plaques with Actinomycetes spp. [72].

In fact, our IHC and FISH data suggest that Chlamydia spp. can exist in aggregate forms as suggested on other systems $[60,66]$. Furthermore, environmental stressors are known to push Chlamydia into a state of persistence, in which they are viable but non-infectious [73]. Persistent like morphological characteristics of Chlamydia have been identified in vivo [74] and several studies have shown resistance of chlamydial infection to antibiotics both in vitro and in vivo [75].

Our confocal microscopy data suggest a very specific spatial distribution of Chlamydia in the Borrelia biofilm. Previous studies suggested that the different bacteria in multi-species biofilms could have specific spatial distribution which supports our confocal image findings showing that Chlamydia is localized in the middle of Borrelia biofilm rather than randomly distributed [42, 77, 78]. Our confocal analyses also demonstrated that the Borrelia/Chlamydia-positive biofilm structure is surrounded by alginate. The observation raises the question about which organism secretes alginate rich protective matrix. While studies show that Chlamydiae-infected cell cultures express a glycolipid that is similar to alginate in its polysaccharide content and molecular weight [76], our data suggests that the alginate being expressed is probably secreted by Borrelia burgdorferi and not by Chlamydia because all Chlamydia negative biofilms are positive for alginate.

Ticks are capable of inoculating and harvesting several different pathogens upon infection to the host organism. A study conducted in Switzerland and Algeria evaluated ticks and fleas for the presence of Chlamydiales DNA and found ticks to be a possible vector for transmission of Chlamydia spp. [50]. The same group in 2015 then reported a higher prevalence and diversity of Chlamydiales DNA in ticks [51]. Another study supported and confirmed the presence of Chlamydia-related organism in ticks [52], and they also found sequences similar to Chlamydia DNA in human skin biopsies. The study screened skin biopsies of patients with suspected history of tick bite and reported Chlamydia DNA in $85 \%$ Borrelia PCR positive biopsies and $71 \%$ positive for Chlamydia DNA in Borrelia PCR negative skin biopsies [52].

Mono-species biofilms alone have proven to be 100 to 1000 times more resistant to antibiotics, leading to persistent infections [79]. Our research group has demonstrated the extraordinary resistance of Borrelia biofilms to several antibiotics in vitro [22, 80], which may explain the persisting symptoms observed in Lyme patients. Multi-species biofilms are being studied extensively in relation to several chronic infections. Chronic wound infections in a porcine model showed increased resistance to antimicrobial activity upon infection with Staphylococcus aureus in a multi-species biofilm form $[39,81,82]$. Pulmonary infections in cystic fibrosis patients have been suggested to contain several different airway pathogens making them more complex and resistant to treatments [40]. Studies have identified Dolosigranulum pigrum and Pseudomonas aeruginosa in biofilm form in pulmonary infections and have shown increased resistance to antimicrobial treatments [40]. Diabetic foot ulcers show polymicrobial infection involving $S$. aureus, $P$. aeruginosa, and $E$. coli at the site of infection, slowing the healing process and, in some cases, leading to antimicrobial resistance [83]. These findings strongly suggest that microbial communities behave synergistically with each other in a mixed biofilm form.

The symptoms observed during Lyme infection are very similar to those of chlamydial infection [62, 63]. Arthritis is one of the major symptoms observed in both of these bacterial infections, and a study suggested the intra-articular co-infection of Chlamydia trachomatis and Borrelia burgdorferi in patients with oligoarthritis [63]. Furthermore, Chlamydia and Borrelia DNAs were found in the synovial fluid of patients with undifferentiated oligoarthritis [84].

Another example for skin infections, which can be caused by Borrelia or Chlamydia, is erythema nodosum, a condition leading to skin inflammation with painful, red deep-seated nodules $[62,85]$. The skin condition erythema multiforme has been also associated with Borrelia and C. pneumoniae infections $[86,87]$.

Furthermore, C. pneumonia infections have been linked to atherosclerosis and well characterized in atherosclerotic plaques [58]. Lyme carditis is one of the chronic infections of Lyme disease, and an independent study reported seropositivity results for anti-Borrelia $\mathrm{IgG}$ antibodies in carotid atherosclerosis [88]. In addition, a recent study observed biofilm formation in atherosclerotic plaques, which indeed suggests that biofilms could be present in cardiac tissues and be a part of the biofilm community with several other species $[89,90]$.

The obvious question is whether multi-species biofilms could have even higher antibiotic resistance for antibiotics than mono-species biofilm. In a synergistic relationship, both biofilm partners should provide advantage for the whole community [42]. The obvious question is why Borrelia and Chlamydia can be found together so frequently and how they can build symbiotic relationships. Chlamydia, for example, cannot produce the ATP molecule for its energetic processes [58-61]. Therefore, it is possible that Borrelia must provide ATP inside the biofilm structure. Furthermore, Borrelia biofilm is known to have a very organized structure that confers high resistance to environmental stressors $[19,20,21]$; therefore, Borrelia could also provide the necessary shelter for Chlamydia. 
Conversely, Chlamydia could supply iron necessary for Borrelia. Several studies have reported that Borrelia uses manganese instead of iron for its own biological processes [91, 92]. Yet, iron appears to play a crucial role in biofilm formation by stabilizing the polysaccharide matrix, as was shown in $S$. aureus and $P$. aeruginosa biofilms [93-95]. Moreover, in a multi-species biofilm of Candida albicans and $P$. aeruginosa, iron triggers virulence of the bacterial pathogens and can cause significant damage to the host [96]. Relating the role of Chlamydia in the biofilm form with Borrelia could suggest that they have a symbiotic relation.

In summary, our data provides strong evidence for the coexistence of Chlamydia spp. with Borrelia biofilms in human skin biopsies of BL lesions with their involvement in Borrelia biofilms. This study warrants further research to understand the physiological role of mixed biofilms in chronic Lyme disease.

\section{Abbreviations}

ATCC - American Type Culture Collection

BL - Borrelial lymphocytoma

BSA - bovine serum albumin

BSK-H - Barbour-Stoner-Kelly H

DIC - differential interference contract microscopy

EM - erythema migrans

EDTA - ethylenediaminetetraacetic acid

FAM - 6-fluorescein amidite

FFPE - formalin-fixed, paraffin-embedded

FISH - fluorescent in situ hybridization

FITC - fluorescein isothiocyanate

H\&E - hematoxylin and eosin

IHC - immunohistochemistry

OmpA - major outer membrane protein A

PBS - phosphate-buffered saline

PCR - polymerase chain reaction

RT - room temperature

SSC - saline sodium citrate

\section{Funding Sources}

This work was supported by grants from the University of New Haven, National Philanthropic Trust, LivLyme Foundation, Lyme Warriors and CT Lyme Riders scholarships to KG and KW. We also thank the Schwartz Research foundation for the donation of the Leica DM2500 microscope, as well as the Hamamatsu ORCA Digital Camera.

\section{Authors' Contribution}

ES conceptualized, designed, and supervised the study, analyzed and interpreted data, obtained funding, and wrote the manuscript. KG designed and performed experiments, analyzed and interpreted data, and wrote manuscript. KW, JT, and GG designed and performed experiments. AM analyzed and interpreted data. BZ conceptualized and designed the study. All authors had full access to all data in the study and take responsibility for the integrity of the data and the accuracy of the data analysis.

\section{Conflict of Interest}

The authors have declared that no competing interest exists.

Acknowledgements. The authors would like to thank Dr. Gerald B. Pier (Harvard University) for the anti-alginate antibody. We also thank Dr. Dougles Brash and Dr. Joseph J. Burrascano for their helpful suggestions for the final manuscript.

\section{References}

1. Burgdorfer W, Barbour AG, Hayes SF, Benach JL, Grunwaldt E, Davis JP. Lyme disease-a tick-borne spirochetosis?. Science. 1982;216:1317-19.

2. Lane RS, Piesman J, Burgdorfer W. Lyme borreliosis: relation of its causative agent to its vectors and hosts in North America and Europe. Annu Rev Entomol. 1991;36:587-609.

3. Baranton G, Postic D, Saint Girons I, Piffarettiet JC, Assous M, Grimont PA. Delineation of Borrelia burgdorferi sensu stricto, Borrelia garinii sp. nov., and group VS461 associated with Lyme borreliosis. Int J Syst Bacteriol. 1992;42:378-83.

4. Steere AC, Coburn J, Glickstein L. The emergence of Lyme disease. J Clin Invest. 2004;113:1093-101.

5. Rudenko N, Golovchenko M, Grubhoffer L, Oliver JH. Updates on Borrelia burgdorferi sensu lato complex with respect to public health. Ticks Tick Borne Dis. 2011;2:123-8.

6. Mead PS. Epidemiology of Lyme Disease. Infect Dis Clin North Am. 2015;29:87-210

7. Ackermann R, Kabatzki J, Boisten HP, Steere AC, Grodzicki L, Hartug $\mathrm{S}$, Runne U. Ixodes ricinus spirochete and European erythema chronicum migrans disease. Yale J Biol Med. 1984;57:573-80.

8. Eisendle $\mathrm{K}$, Zelger $\mathrm{B}$. The expanding spectrum of cutaneous borreliosis. G Ital Dermatol Venereol. 2009;144:157-71

9. Eisendle K, Grabner T, Zelger B. Focus floating microscopy: "Gold Standard" for cutaneous Borreliosis? Am J Clin Pathol. 2007;127:213-22.

10. Wormser GP. Clinical practice. Early Lyme disease. N Engl J Med. 2006;354:2794-801

11. Müllegger RR, Glatz M. Skin manifestations of lyme borreliosis: diagnosis and management. Am J Clin Dermatol. 2008;9:355-68.

12. Kandhari R, Kandhari S, Jain S. Borrelial lymphocytoma cutis: a diagnostic dilemma. Indian J Dermatol. 2014;59:595-607.

13. Cary NR, Fox B, Wright DJ, Cutler SJ, Shapiro LM, Grace AA. Fatal Lyme carditis and endodermal heterotopia of the atrioventricular node. Postgrad Med J. 1990;66:134-6.

14. Hildenbrand P, Craven DE, Jones R, Nemeskal P. Lyme neuroborreliosis: manifestations of a rapidly emerging zoonosis. AJNR Am J Neuroradiol. 2009;30:1079-87.

15. Miklossy J. Chronic or late lyme neuroborreliosis: analysis of evidence compared to chronic or late neurosyphilis. Open Neurol J. 2012;6:146-57.

16. Scheffold N, Herkommer B, Kandolf R, May AE. Lyme carditisdiagnosis, treatment and prognosis. Dtsch Arztebl Int. 2015;112:202-8.

17. Smith BG, Cruz AI, Milewski MD, Shapiro ED. Lyme disease and the orthopaedic implications of lyme arthritis. J Am Acad Orthop Surg. 2011;19:91-100.

18. Lantos PM. Chronic Lyme disease. Infect Dis Clin North Am 2015;29:325-40

19. Sapi E, Bastian SL, Mpoy CM, Scott S, Rattelle A, Pabbati N, et al. Characterization of biofilm formation by Borrelia burgdorferi in vitro. PLoS One. 2012;7:1-11.

20. Timmaraju VA, Theophilus PAS, Balasubramanian K, Shakih S, Luecke DF, Sapi E. Biofilm formation by Borrelia sensu lato. FEMS Microbiol Lett. 2015;362:fnv120. doi: 10.1093/femsle/fnv120.

21. Sapi E, Balasubramanian K, Poruri A, Maghsoudlou JS, Socarras KM,

et al. Evidence of in vivo existence of Borrelia biofilm in Borrelial Lymphocytomas. Eur J Microbiol Immunol (Bp). 2016;6:9-24

22. Sapi E, Kaur N, Anyanwu S, Datar A, Patel S, Rossi JM, et al. Evaluation of in vitro antibiotic susceptibility of different morphological forms of Borrelia burgdorferi. Infect Drug Resist. 2011;4:97-113.

23. Costerton JW, Stewart PS, Greenberg EP. Bacterial biofilms: a common cause of persistent infections. Science. 1999;284:1318-22.

24. Sutherland I. Biofilm exopolysaccharides: a strong and sticky framework. Microbiol. 2001;147:3-9.

25. Hall-Stoodley L, Costerton JW, Stoodley P. Bacterial biofilms: from the natural environment to infectious diseases. Nat Rev Microbiol. 2004:2:95-108.

26. Flemming HC, Neu TR, Wozniak DJ. The EPS matrix: the "house of biofilm cells". J Bacteriol. 2007;189:7945-7.

27. Jiao Y, Cody GD, Harding AK, Wilmes P, Schrenk M, et al Characterization of extracellular polymeric substances from acidophilic microbial biofilms. Appl Environ Microbiol. 2010;76:2916-22

28. Amato SM, Fazen CH, Henry TC, Mok WW, Orman MA, et al. The role of metabolism in bacterial persistence. Front Microbiol. 2014;5:70. doi: 10.3389/fmicb.2014.00070

29. Conlon BP, Rowe SE, Lewis K. Persister cells in biofilm associated infections. Adv Exp Med Biol. 2015;831:1-9.

30. Lewis K, Shan Y. Why tolerance invites resistance. Science. 2017;355:96.

31. Lopes SP, Ceri H, Azevedo NF, Pereira MO. Antibiotic resistance of mixed biofilms in cystic fibrosis: impact of emerging microorganisms on treatment of infection. Int J Antimicrob Agents. 2012;40:260-3.

32. Sun F, Qu F, Ling Y, Mao P, Xia P, Chen H, Zhou D. Biofilmassociated infections: antibiotic resistance and novel therapeutic strategies. Future Microbiol. 2013;8:877-86.

33. Römling U, Balsalobre C. Biofilm infections, their resilience to therapy and innovative treatment strategies. J Intern Med. 2012;272:541-61.

34. Bjarnsholt $\mathrm{T}$. The role of bacterial biofilms in chronic infections. APMIS Suppl. 2013;136:1-51.

35. Petersen NT, Høiby N, Mordhorst CH, Lind K, Flensborg EW, Bruun B. Respiratory infections in cystic fibrosis patients caused by virus, chlamydia and mycoplasma-possible synergism with Pseudomonas aeruginosa. Acta Paediatr Scand. 1981;70:623-8.

36. Fiedler T, Köller T, Kreikemeyer B. Streptococcus pyogenes biofilmsformation, biology, and clinical relevance. Front Cell Infect Microbiol. 2015;5:15. doi: 10.3389/fcimb.2015.00015. 
37. Delcaru C, Alexandru I, Podgoreanu P, Grosu M, Stavropoulos E, Chifiriuc MC, Lazar V. Microbial biofilms in urinary tract infections and prostatitis: Etiology, pathogenicity, and combating strategies. Pathogens. 2016;5:65. doi:10.3390/pathogens5040065.

38. Wang J, Foxman B, Mody L, Snitkin ES. Network of microbial and antibiotic interactions drive colonization and infection with multidrug-resistan organisms. Proc Natl Acad Sci USA. 2017;14:10467-72. doi: 10.1073/ pnas. 1710235114

39. Dalton T, Dowd SE, Wolcott RD, Sun Y, Watters C, Griswold JA, et al. An in vivo polymicrobial biofilm wound infection model to study interspecies interactions. PLoS ONE. 2011;6:e27317.

40. Lopes SP, Ceri H, Azevedo NF, Pereira MO. Antibiotic resistance of mixed biofilms in cystic fibrosis: impact of emerging microorganisms on treatment of infection. Int J Antimicrob Agents. 2012;40:260-3.

41. Burmølle M, Webb JS, Rao D, Hansen LH, Sørensen SJ, Kjelleberg S. Enhanced biofilm formation and increased resistance to antimicrobial agents and bacterial invasion are caused by synergistic interactions in multispecies biofilms. Appl Environ Microbiol. 2006;72:3916-23.

42. Elias S, Banin E. Multi-species biofilms: living with friendly neighbors. FEMS Microbiol Rev. 2012; 36(5):990-1004.

43. Brown JS: Oral biofilms, periodontitis and pulmonary infections. Oral Dis. 2007:13:513-4.

44. Burmølle M, Ren D, Bjarnsholt T, Sørensen SJ. Interactions in multispecies biofilms: do they actually matter? Trends Microbiol. 2014;22:84-91.

45. Berghoff W. Chronic Lyme disease and co-infections: Differential diagnosis. Open Neurol J. 2012;6:158-78.

46. Caulfield AJ, Pritt BS. Lyme disease coinfections in the United States. Clin Lab Med. 2015;35:827-46.

47. Diuk-Wasser MA, Vannier E, Krause PJ. Coinfection by Ixodes tickborne pathogens: Ecological, epidemiological, and clinical consequences. Trends Parasitol. 2016:32:30-42.

48. Moutailler S, Valiente Moro C, Vaumourin E, Michelet L, Tran FH, Devillers E, et al. Co-infection of ticks: The rule rather than the exception PLoS Negl Trop Dis. 2016;10:e0004539.

49. Raileanu C, Moutailler S, Pavel I, Porea D, Mihalca AD, Savuta G, Vayssier-Taussat M. Borrelia diversity and co-infection with other tick borne pathogens in ticks. Front Cell Infect Microbiol. 2017;7:36. doi:10.3389/ fcimb.2017.00036

50. Croxatto A, Rieille N, Kernif T, Bitam I, Aeby S, Peter O, Greub G. Presence of Chlamydiales DNA in ticks and fleas suggests that ticks are carriers of Chlamydiae. Ticks Tick Borne Dis. 2014;5:59-365.

51. Pilloux L, Aeby S, Gaümann R, Burri C, Beuret C, Greub G. The high prevalence and diversity of Chlamydiales DNA within Ixodes ricinus ticks suggest a role for ticks as reservoirs and vectors of Chlamydia-related bacteria. Appl Environ Microbiol. 2015;81:8177-82.

52. Hokynar K, Sormunen JJ, Vesterinen EJ, Partio EK, Lilley T, et al. Chlamydia-like organisms (CLOs) in Finnish Ixodes ricinus ticks and human skin. Microorg. 2016;4:28. doi: 10.3390/microorganisms4030028.

53. Tolkki L, Hokynar K, Meri S, Panelius M, Ranki A. Granuloma annulare and morphea: Correlation with Borrelia burgdorferi infections and Chlamydia-related bacteria. Acra Derma Venereol. 2018;98:355-60. doi: 10.2340/00015555-2831.

54. Burnard D, Weaver H, Gilett A, Loader J, Flanagan C, Polkinghome A. Novel Chlamydiales genotype identified in ticks from Australian wildlife. Paras Vec. 2017;10:46. doi: 10.1186/s13071-017-1994-y.

55. Stephens RS, Kalman S, Lammel C, Marathe R, Aravind L, et al. Genome sequence of an obligate intracellular pathogen of humans: Chlamydia trachomatis. Science. 1998;282:754-9.

56. Elwell C, Mirrashidi K, Engel J. Chlamydia cell biology and pathogenesis. Nat Rev Microbiol. 2016;14:385-400.

57. Fields KA, Hackstadt T. The chlamydial inclusion: escape from the endocytic pathway. Annu Rev Cell Dev Biol. 2002;18:221-45.

58. Belland RJ, Ouellette SP, Gieffers J, Byrne GI. Chlamydia pneumoniae and atherosclerosis. Cell Microbiol. 204;6:117-127. doi:10.1046/j.14625822.2003.00352.x.

59. Honarmand $\mathrm{H}$. Atherosclerosis induced by Chlamydophila pneumoniae: A controversial theory. Interdiscip Perspect Infect Dis. 2013;2013:941392.

60. Clausen JD, Christiansen G, Holst HU, Birkelund S. Chlamydia trachomatis utilizes the host cell microtubule network during early events of infection. Mol Microbiol. 1997;25:44-449.

61. Michael RK, Konrad S. Chlamydia psittaci: update on an underestimated zoonotic agent. Pathogens and Dis. 2015;73:1-15.

62. Kousa M, Saikku P, Kanerva L. Erythema nodosum in chlamydial infections. Acta Derm Venereol. 1980;60:319-22

63. Putschky N, Schnarr S, Wollenhaupt J, Zeidler H, Kuipers J. Intraarticular co-infection by Borrelia burgdorferi and Chlamydia trachomatis. Annals of the Rheumatic Diseases. 2001:60:632-4. doi:10.1136/ard.60.6.632.

64. Somani J, Bhullar VB, Workowski KA, Farshy CE, Black CM Multiple drug-resistant Chlamydia trachomatis associated with clinical treatment failure. J Infect Dis. 2000;181:1421-7.

65. Yamaguchi H, Friedman H, Yamamoto M, Yasuda K, Yamamoto Y. Chlamydia pneumoniae resists antibiotics in lymphocytes. Antimicrob Agents Chemother. 2003;47:1972-5.

66. Majeed M, Gustafsson M, Kihlström E, Stendahl O. Roles of $\mathrm{Ca} 2+$ and F-actin in intracellular aggregation of Chlamydia trachomatis in eukaryotic cells. Infect Immun. 1993;61:1406-14.
67. Majeed M, Krause KH, Clark RA, Kihlström E, Stendahl O. Localization of intracellular $\mathrm{Ca} 2+$ stores in $\mathrm{HeLa}$ cells during infection with Chlamydia trachomatis. J Cell Sci. 1999:112·35-44.

68. Sabagh F, Storey CC. The development of polymerase chain reaction (PCR) to detect C. pneumoniae and C. psittaci. J Paramed Sci (JPS). 2010;1:43-52.

69. Rostami NM, Rashidi HB, Aghsaghloo F, Nazari R. Comparison of clinical performance of antigen based-enzyme immunoassay (EIA) and major outer membrane protein (MOMP)-PCR for detection of genital Chlamydia trachomatis infection. Int J Reprod Biomed (Yazd). 2016;14:411-20.

70. Poppert S, Essig A, Marre R, Wagner M, Horn M. Detection and differentiation of chlamydiae by fluorescence in situ hybridization. Appl Environ Microbiol. 2002;68:4081-9.

71. Garg K, Meriläinen L, Franz O, Pirttinen H, Quevedo-Diaz M, Croucher S, Gilbert L. Evaluating polymicrobial immune responses in patients suffering from tick-borne diseases. Sci Rep. 2018;8:15932. doi:10.1038/s41598-018-34393-9.

72. Filoche SK, Anderson SA, Sissons $\mathrm{CH}$. Biofilm growth of Lactobacillus species is promoted by Actinomyces species and Streptococcus mutans. Oral Microbiol Immunol. 2004;19:322-6.

73. Borel N, Pospischil A, Hudson AP, Rupp J, Schoborg RV. The role of viable but non-infectious developmental forms in chlamydial biology. Front Cell Infect Microbiol. 2014;4:97.

74. Phillips Campbell R, Kintner J, Whittimore J, Schoborg RV. Chlamydia muridarum enters a viable but non-infectious state in amoxicillin-treated BALB/c mice. Microbes Infect. 2012;14:1177-85.

75. Sandoz KM, Rockey DD. Antibiotic resistance in Chlamydiae. Future Microbiol. 2010;5:1427-1442.

76. Tolker-Nielsen T, Molin S. Spatial organization of microbial biofilm communities. Microb Ecol. 2000;40:75-84.

77. Stuart ES, Tirrell SM, MacDonald AB. Characterization of an antigen secreted by Chlamydia-infected cell culture. Immunol. 1987;61:527-33.

78. Mitri S, Xavier JB, Foster KR. Social evolution in multispecies biofilms. Proc Natl Acad Sci USA. 2011;108:10839-46.

79. Stewart PS, Costerton JW. Antibiotic resistance of bacteria in biofilms. Lancet. 2001;358:135-8.

80. Theophilus PA, Victoria MJ, Socarras KM, Filsuh KR, Gupta K, Luecke DF: Effectiveness of stevia rebaudiana whole leaf extract against the various morphological forms of Borrelia burgdorferi in vitro. Eur J Microbiol Immunol (Bp). 2015;5:268-80.

81. Davis SC, Ricotti C, Cazzaniga A, Welsh E, Eaglstein WH, Mertz PM. Microscopic and physiologic evidence for biofilm-associated wound colonization in vivo. Wound Repair Regen. 2008;16:23-9.

82. Hotterbeekx A, Kumar-Singh S, Goossens H, Malhotra-Kumar S. In vivo and in vitro interactions between Pseudomonas aeruginosa and Staphylococcus spp. Front Cell Infect Microbiol. 2017;7:106. doi:10.3389/ fcimb.2017.00106.

83. Shanmugam PMJ, Susan SL. The bacteriology of diabetic foot ulcers, with a special reference to multidrug resistant strains. J Clin Diagn Res. 2013;7:441-5

84. Schnarr S, Putschky N, Jendro MC, Zeidler H, Hammar M, Kulpers JG, Wollenhaupt J. Chlamydia and Borrelia DNA in synovial fluid of patients with early undifferentiated oligoarthritis: results of a prospective study. Arthritis Rheum. 2001;44:2679-85

85. Simakova AL, Popov AF, Dadalova OB. Ixodes tick-borne borreliosis with erythema nodosum. Med Parazitol (Mosk). 2005;4:31-2.

86. Hosokawa R, Kobayashi T, Higashino T, Asano C, Ono K, Fijimoto N, Tajima S. Two cases of erythema exsudativum multiforme associated with Chlamydia pneumoniae infection. J Dermatol. 2012;39:306-8.

87. Imashuku S, Kudo N. Chlamydia pneumoniae infection-associated erythema multiforme. Pediatr Rep. 2013;5:35-7. doi: 10.4081/pr.2013.e9.

88. Völzke H, Wolff B, Lüdemann J, Guertler L, Kramer A, John U, Felix SB. Seropositivity for anti-Borrelia IgG antibody is independently associated with carotid atherosclerosis. Atherosclerosis. 2016;184:108-12.

89. Allen HB, Boles J, Morales D, Ballal S, Joshi SG. Arteriosclerosis: The novel finding of biofilms and innate immune system activity within the plaques. J Med Surg Pathol. 2016;1:135

90. Kang SG, Chung WC, Song SW, Joo KR, Lee H, Kang D, Lee JS, Lee KM. Risk of artherosclerosis and Helicobacter pylori infection according to CD14 promotor polymorphism in healthy Korean population. Gastroenterol Res Pract. 2013; 2013:570597.

91. Posey JE, Gherardini FC. Lack of a role for iron in the Lyme disease pathogen. Science. 2000;288:1651-3.

92. Troxell B, Xu H, Yang XF. Borrelia burgdorferi, a pathogen that lacks iron, encodes manganese-dependent superoxide dismutase essential for resistance to streptonigrin. J Biol Chem. 2012;287:19284-93.

93. Berlutti F, Morea C, Battistoni A, Sarli S, Cipriani P, Superti F, Ammendolia MG, Valenti P. Iron availability influences aggregation, biofilm, adhesion and invasion of Pseudomonas aeruginosa and Burkholderia cenocepacia. Int J Immunopathol Pharmacol. 2005;18:661-70.

94. Lin MH, Shu JC, Huang HY, Cheng YC. Involvement of iron in biofilm formation by Staphylococcus aureus. PLoS One. 2012;7:e34388. doi: 10.1371/journal.pone.0034388.

95. Weinberg ED. Suppression of bacterial biofilm formation by iron limitation. Med Hypot. 2004;63:863-5.

96. Trejo-Hernández A, Andrade-Domínguez A, Hernández M, Encarnación S. Interspecies competition triggers virulence and mutability in Candida albicans-Pseudomonas aeruginosa mixed biofilms. ISME J. $2014 ; 8: 1974-88$ 